\title{
Long-Term Trends in Domestic US Passenger Travel: \\ The Past 110 Years and the Next 90
}

\author{
Andreas W. Schäfer \\ Precourt Energy Efficiency Center, Stanford University \\ Yang \& Yamazaki Environment \& Energy Building \\ 473 Via Ortega, Room 387, Stanford, CA 94305-4205 \\ aschafer@stanford.edu, 650 723-0884 \\ and \\ UCL Energy Institute, University College London \\ a.schafer@ucl.ac.uk, 020 3108-5925
}

\begin{abstract}
Based upon a long-term historical data set of US passenger travel, a model is estimated to project aggregate transportation trends through 2100 . One of the two model components projects total mobility (passenger-km traveled) per capita based on per person GDP and the expected utility of travel mode choices (logsum term). The second model component has the functional form of a logit model, which assigns the projected travel demand to competing transportation modes. An iterative procedure ensures the average amount of travel time per person to remain at a pre-specified level through modifying the estimated value of time. The outputs from this model can be used as a first-order estimate of a future benchmark against which the effectiveness of various transportation policy measures or the impact of autonomous behavioral change can be assessed.
\end{abstract}

Keywords: passenger travel; time series model; mode choice; travel time budget; peak car; scenario 


\section{Introduction}

Since 1900, US domestic passenger-km traveled (PKT) per person has grown at an average rate of nearly $3.3 \%$ per year, reaching about $25,000 \mathrm{~km}$ in 2010 . This enormous growth was enabled by systematic shifts towards ever-faster transportation modes. While electric streetcars and steam-powered railways dominated the US transportation system in the early $20^{\text {th }}$ century, light-duty vehicles (LDVs) experienced a peak in market share at around 1960, and then dropped to around $87 \%$ in 2010 because of the stronger growing domestic air travel. Obviously these shifts toward ever-faster modes occurred in distinct markets; while automobiles have largely displaced mass transit in urban transport, aircraft have been gaining market share in intercity travel on the cost of automobiles.

Figures 1 a, b report the long-term evolution of US passenger travel between 1900 and 2010 in terms of total travel demand per person and total PKT and the relative importance of the three major motorized transportation modes, LDVs, public surface modes, and aircraft.

[Figure 1a-b]

The question underlying this paper is how the historical growth in per capita PKT and its distribution across modes may continue to evolve over the next 90 years if the key determinants underlying the historical growth in travel remain largely unchanged. Answering this question is important for transportation infrastructure planning and policies aiming to mitigate oil import dependence and environmental impacts. For example, several studies anticipated the possibility of a peak in car travel in high-income countries (Schäfer and Victor 2000; and more recently, Millard-Ball and Schipper 2010; Goodwin 2012). If such "peak car" materializes, further extensions of road infrastructure in anticipation of continuous growth could waste economic resources. Better understanding the range of plausible futures is especially important for commercial air travel, which has grown at almost twice the rate of LDV transportation since 
1980. Should this growth trend continue, the implications for airport infrastructure planning, fuel supply, and environmental impact could be massive.

Despite the pressing relevance of this issue, surprisingly little work exists that projects total transportation demand of any country and its distribution across modes far into the future. Two broad approaches could be identified. One approach uses national or world regional level data to project travel demand by major mode of transport separately. Examples include the transportation module of the Energy Information Administration's NEMS model (EIA 2009) and the International Energy Agency's global Mobility Model (Fulton et al. 2009). While convenient to implement, this approach cannot simulate the changing relative importance between competing transportation modes as a result of alterations in prices and speeds for specific modes. The second approach follows a scenario method, in which expert-based projections of mobility determinants are converted into PKT and the distribution across modes, such as in the RAND study on the future of US mobility (Zmud et al. 2013). While this approach encompasses a wide range of possible transportation futures, it does not provide a model that can be used to conveniently test the outcomes of alternative assumptions. ${ }^{1}$

In contrast, the approach presented here uses time series models to project total travel demand and to assign the projected PKT to the competing modes of transportation shown in Figure 1. The resulting system of three equations is capable of simulating changes in travel demand and mode share in response to changes in income, prices, and door-to-door speeds. The specification of this model is sufficiently simple and general to allow application to other parts of the world. In fact, the intention is to use this approach to ultimately arrive at a superior model of global travel demand compared to that described by Schäfer and Victor (2000). The

\footnotetext{
${ }^{1}$ Another approach, which goes beyond the scope of this paper, assigns subnational projections of surface transportation demand to network-based supply models, thus significantly increasing complexity. The UK National Transport Model covers nine surface transport modes, eight trip purposes, and households located within nearly 2,500 zones (Department for Transport 2009). Partly owing to the increased complexity, the forecasting time horizon of this model is typically a few decades.
} 
specification and estimation of the system of three equations with a unique long-term U.S. historical dataset is this paper's key contribution.

The subsequent section continues with a description of the available data of key determinants of passenger travel. Thereafter, the growth factor and choice models are presented. After estimating the model, it is evaluated under different scenario conditions and the shortcomings are addressed. This paper's conclusions are summarized in a final section. The electronic supplementary material summarizes the extensive model input data.

\section{Characterization of the Available Data}

Many factors affect the demand for passenger travel, including the distribution of income, travel costs, perceived levels of comfort and safety, door-to-door speed, availability of public transport modes, the use of land, access to and use of information and telecommunication technologies, attitudes, and social norms. However, because the model presented here is estimated with historical time-series data, it can only explicitly account for the most important factors for which data series already exist or can be estimated relatively easily. This limitation has to be kept in mind when interpreting the results (see below section on caveats).

On an aggregate level, growth in per person income, here approximated by per capita GDP, has been the key driver of the historical increase in passenger travel. Figure 2a depicts the long-term historical trend; since 1900, per person GDP has grown at an average rate of 2.1\% per year. During the same period, the US population has grown from 76.1 to 310.2 million (Figure $2 \mathrm{~b}$ ), an average of $1.3 \%$ per year, causing total GDP to increase by $3.4 \%$ per year. Dividing total GDP by the total work hours yields the GDP-based wage rate. According to Figure 2c, the wage rate has quintupled since 1900 , from some $\$ 5$ to $\$ 26$ per hour. (All US $\$$ are in 2010 currency).

The growth in PKT per person was enabled by roughly stable average travel costs, which are shown in Figure $2 \mathrm{~d}$. This stability was the result of two diverging trends, a slight 
increase in travel costs by LDVs and public surface transportation means and a significant drop in airfare by nearly 80\% since 1929 (Schäfer 2013). Another enabler of the growth in travel demand was the increase in door-to-door travel speeds, most prominently in aviation with the transition from the piston to the jet engine (Figure $2 \mathrm{e}$ ).

Finally, travel demand and mode choice are determined by the amount of time people spend travelling. Towards the end of the 1970s, the late transportation researcher Yacov Zahavi discovered remarkably stable time expenditures by urban travelers, who perform at least one trip with a motorized mode at a given day (Zahavi 1981). Other researchers generalized his hypothesis to the entire population of cities and countries using all modes and found similar levels of stability (e.g., Marchetti 1994). Using data from travel and time use surveys, Figure $2 f$ illustrates the stability of the travel time budget (TTB) for very different settings (Schäfer and Victor 2000; Schäfer et al. 2009). The average amount of time spent travelling appears to be between 1 and 1.5 hours per person per day (corresponding to roughly $5 \%$ of the daily amount of time), irrespective of the income level. While roughly stable at aggregate levels, travel time expenditures per person vary at finer levels of resolution (for a thorough discussion, see Mokhtarian and Chen 2004). Also shown is the historical trend of the estimated per person travel time associated with motorized US passenger transportation, which results from the sum of the ratios of the daily per person PKT by mode and the respective average travel speeds shown in Figures 1a and 2e. While time spent on non-motorized travel has declined (not shown here), the estimated travel time dedicated to motorized travel has been increasing. More recently, the latter has even exceeded the level of the US travel survey-based total travel time of 1.25 hours per person per day in 2009 (Department of Transportation 2013), which may suggest that travel survey-based travel times tend to be underestimated, especially if also considering non-motorized travel. In fact, recent GPS sensor-based travel time measurements resulted in significantly higher levels (Ben-Akiva 2013). Thus, the model presented below projects total PKT per person and its distribution across modes for any user-specified trajectory of travel time. 
[Figure 2a-f]

\section{The Model and its Components}

Starting from Schäfer and Victor (2000), the model consists of a system of three equations, one describing total travel demand and two equations describing the related mode shares. Jointly, per person PKT, mode shares, and door-to-door speeds yield the daily per person travel time. Should per person travel time exceed the exogenously specified TTB (or any specified development over time), the value of time coefficient in the three equations is increased and total travel demand and mode shares are recalculated. This procedure, which is implemented in Matlab, is repeated until convergence is achieved, that is, the estimated travel time per person is "sufficiently close" to the specified TTB.

\section{Total Travel Demand Model}

The total travel demand model relates per person PKT (pkt) to an autoregressive term, per person GDP ( $g d p)$, the logsum term, i.e., the logarithm of the sum of the exponentiated utility terms of the considered transport modes $(m \in M)$, which include the generalized travel costs (described below in more detail), and a dummy variable accounting for exogenous shocks on per person PKT, such as the first oil crisis, in log-linear form as shown in equation 1.

$$
\begin{aligned}
\ln p k t_{t}=\gamma_{0}+ & \gamma_{1} \ln p k t_{t-1}+\gamma_{2} \ln g d p_{t}+\gamma_{3} \ln g d p_{t-1} \\
& +\gamma_{4} \ln \left(\ln \sum_{M} e^{V_{m, t}}\right)+\gamma_{5} \ln \left(\ln \sum_{M} e^{V_{m, t-1}}\right)+\delta \cdot D+\varepsilon_{t}
\end{aligned}
$$

Feeding the generalized travel costs via the logsum expression into this growth factor model allows changes in travel costs and speeds (such as traffic congestion) to affect total 
travel demand. For example, a declining average travel speed due to traffic congestion on the road or in the air will cause the related generalized costs to increase. Therefore the utility and growth in travel demand will decline.

\section{Mode Choice Model}

The tested specifications of the multinomial logit (MNL) model are ultimately based on the following observed utility function

$$
V_{m, t}=\beta_{m}+\beta_{1} S h_{m, t-1}+\beta_{2} \frac{T T_{m, t}}{D_{m, t}}+\beta_{3} \frac{C_{m, t}}{(G D P / h)_{t}}
$$

with Sh denoting the mode share in previous periods, $T T$ mean travel time (in $\mathrm{h}$ ), $D$ mean distance (in $\mathrm{km}$ ), C mean travel costs (in $\$ / p k m$ ), GDP gross domestic product (in $\$$ ), $h$ the total work hours of the population, subscript $m$ mode, and subscript $t$ time. The alternative specific constant $\beta_{m}$ was set to 0 for aircraft. The lagged share of mode $m$ represents an inertia: travellers are constrained in their mode choice by the available modes, availability of information, and their habits. Thus, mode choice at time $t$ is partly determined by that at time $t-1$. Note that the travel costs by each mode $C_{m}$ are normalized by gdp per hour (total GDP over total work hours, i.e., the GDP-based wage rate), because they affect utility differently as income levels change over time. As with the travel costs, higher time expenditures per distance traveled impact utility more strongly at higher levels of income or wage rate. A variant of equation 2 is shown in equation 3 , where the lagged term of the respective mode share is logarithmic

$$
V_{m, t}=\beta_{m}+\beta_{1} \ln \left(S h_{m, t-1}\right)+\beta_{2} \frac{T T_{m, t}}{D_{m, t}}+\beta_{3} \frac{C_{m, t}}{(G D P / h)_{t}}
$$


A simple manipulation of equation 2 yields

$$
V_{m, t}=\beta_{m}+\beta_{1} S h_{m, t-1}+\beta_{3}\left(\frac{V O T}{S_{m, t}}+\frac{C_{m, t}}{(G D P / h)_{t}}\right)
$$

where the value of time (VOT) is substituted for $\beta_{2} / \beta_{3}$ and door-to-door speed $S_{m, t}$ is substituted for distance over travel time. Because the travel costs by each mode $C_{m}$ are divided by the GDP-based wage rate, the dimension of VOT equals 1 . The VOT can thus be interpreted as the fraction of $G D P / h$ that is being spent on transportation. This can be seen from equation 3 , when dividing the speed (or normalized time) coefficient $\beta_{2}$ by the cost coefficient $\beta_{3} /(G D P / h)$.

Correspondingly, the utility equations for the three modes considered here result in:

$$
\begin{aligned}
& V_{L D V, t}=\beta_{L D V}+\beta_{1} S h_{L D V, t-1}+\beta_{3}\left(\frac{V O T}{S_{L D V, t}}+\frac{C_{L D V, t}}{(G D P / h)_{t}}\right) \\
& V_{P u b, t}=\beta_{P u b}+\beta_{1} S h_{P u b, t-1}+\beta_{3}\left(\frac{V O T}{S_{P u b, t}}+\frac{C_{P u b, t}}{(G D P / h)_{t}}\right) \\
& V_{A i r, t}=\beta_{1} S h_{A i r, t-1}+\beta_{3}\left(\frac{V O T}{S_{A i r, t}}+\frac{C_{\text {Air }, t}}{(G D P / h)_{t}}\right)
\end{aligned}
$$

The multinomial logit model takes the form (see, e.g., Ben-Akiva and Lerman 1984):

$$
S h_{m, t}=\frac{e^{V_{m, t}}}{\sum_{M} e^{V_{m, t}}} \quad \text { with } m \in M
$$


The independence of irrelevant alternatives (IIA) property allows conveniently deriving the odds ratios $S h_{L D V, t} / S h_{A i r, t}$ and $S h_{P u b, t} / S h_{A i r, t}$ and estimating the MNL model simultaneously with the total travel demand model (equation 1).

$$
\begin{aligned}
\ln \left(\frac{S h_{L D V}}{S h_{A i r}}\right)_{t}= & V_{L D V, t}-V_{A i r, t} \\
& =\beta_{L D V}+\beta_{1}\left(S h_{L D V}-S h_{A i r}\right)_{t-1} \\
& +\beta_{3}\left(\frac{V O T}{S_{L D V, t}}-\frac{V O T}{S_{A i r, t}}+\frac{C_{L D V, t}-C_{A i r, t}}{(G D P / h)_{t}}\right)+\varepsilon_{t} \\
\ln \left(\frac{S h_{P u b}}{S h_{A i r}}\right)_{t}= & V_{P u b, t}-V_{A i r, t} \\
& =\beta_{P u b}+\beta_{1}\left(S h_{P u b}-S h_{A i r}\right)_{t-1} \\
& +\beta_{3}\left(\frac{V O T}{S_{P u b, t}}-\frac{V O T}{S_{A i r, t}}+\frac{C_{P u b, t}-C_{A i r, t}}{(G D P / h)_{t}}\right)+\varepsilon_{t}
\end{aligned}
$$

If using the natural logarithm $\beta_{1} \ln S h_{m, t-1}$ as the lagged transportation mode share such as in equation 3 , equation 7 results in

$$
\begin{aligned}
& \ln \left(\frac{S h_{L D V}}{S h_{\text {Air }}}\right)_{t}=\beta_{L D V}+\beta_{1} \ln \left(\frac{S h_{L D V}}{S h_{\text {Air }}}\right)_{t-1}+\beta_{3}\left(\frac{V O T}{S_{L D V, t}}-\frac{V O T}{S_{A i r, t}}+\frac{C_{L D V, t}-C_{A i r, t}}{(G D P / h)_{t}}\right)+\varepsilon_{t} \\
& \ln \left(\frac{S h_{P u b}}{S h_{\text {Air }}}\right)_{t}=\beta_{P u b}+\beta_{1} \ln \left(\frac{S h_{P u b}}{S h_{\text {Air }}}\right)_{t-1}+\beta_{3}\left(\frac{V O T}{S_{P u b, t}}-\frac{V O T}{S_{A i r, t}}+\frac{C_{P u b, t}-C_{A i r, t}}{(G D P / h)_{t}}\right)+\varepsilon_{t}
\end{aligned}
$$

The introduction of the natural logarithm thus results in an autoregressive model similar to that of total travel in equation 1 . This specification may better capture the dynamics of the time series data. In addition, because the coefficient $\beta_{1}$ indicates the influence of the respective odds ratio of previous time steps on the odds ratio at time $t$ as a fraction, it is more easily interpretable compared to its specification in equation 7. 
Including Air Traffic Delay

Assuming, for simplicity, steady state airport operations and a M/D/1 queuing system (memoryless arrival rate / deterministic service rate / aircraft being served one after one), air transportation system delay results in (Gross et al. 2008)

$$
\text { Delay }=0.5 \frac{\rho}{1-\rho}=0.5 \frac{\frac{R P K}{\text { Capacity }}}{1-\frac{R P K}{\text { Capacity }}}
$$

with $\rho$ being the system utilization ratio, here defined as the ratio of system (domestic plus international) revenue passenger km (RPK) and total US airport capacity. Recent (2005-2010) arrival delay data of around 10-12\% (Department of Transportation 2012) thus imply an average capacity utilization ratio of around $20 \% .^{2}$ Given a system RPK of 1,284 bln in 2010, total airport capacity would correspond to the fivefold level or 6,420 bln RPK. According to equation 9, an increase in RPK at a fixed capacity will increase air traffic delay, initially modestly but more rapidly as RPK approaches capacity $(\rho \rightarrow 1)$. As a consequence, gate-to-gate and thus door-todoor speeds $\left(S_{A i r, t}\right.$ in the utility equations above) will decline.

\section{Model Estimation}

\footnotetext{
${ }^{2}$ Arrival delay is defined as the difference between actual and scheduled arrival time as a share of scheduled flight time.
} 
Equations $1 \& 7$ and $1 \& 8$ share several RHS variables. Thus each of these systems of equations was estimated simultaneously. Because the error terms are likely to be correlated within each system of equations - due to the limited number of attributes included in the observed utility functions - the two systems of equations were estimated using Seemingly Unrelated Regression with the NLSUR code embedded in Stata 12.1. Table 1 reports the estimation results.

Both mode choice specifications, i.e., the lagged mode share and the natural logarithm of the lagged mode share, were estimated using the full (1945-2010) data set (columns 1,3) and a reduced data set with a later start year, because some of the key coefficients turned out to be statistically insignificant at even a $90 \%$ confidence level. The longest possible time series that resulted in statistically significant coefficients at a 95\% confidence interval was 1961-2010 for equations $1 \& 7$ (column 2) and $1960-2010$ for equations $1 \& 8$ (column 5 ). The respective coefficient estimates changed only slightly with the change in the time series data used for their estimate-the confidence intervals from nearly all estimated coefficients overlap. In addition, the fourth data column reports coefficient estimates that are based on an exogenous input of VOT for the system of equations $1 \& 8$ to overcome its insignificant parameter estimate when using the entire 1945-2010 time series. The VOT coefficient then resulted from manual iterations for the highest $\mathrm{R}^{2}$.

The sensitivity of the statistical significance of the estimated coefficients with respect to the length of the time series can be attributed at least in part to the aggregate nature of the underlying time series data. The national-level data was also influenced by variables that are not explicitly represented in the above model, such as changes in land-use, transportation technologies, life-styles, the deregulation of the airline industry, and other factors. These influences have changed over time, which helps explain the dependency of the precision of the estimated coefficients on the length of the time series data. While higher resolution data would be preferable for reducing the confidence interval of the estimated parameters, stable long-term 
trends can be best identified on a highly aggregate level; these conflicting needs form an unavoidable dilemma.

The sign and size of all estimated coefficients in columns 1-5 are consistent with theory. The VOT ranges from $11-32 \%$ of the GDP-based wage rate (total GDP over total work hours), which is about twice the income-based wage rate. The corresponding VOT of $22-64 \%$ of the income-based wage rate compares well to other estimates in the literature (see, e.g, Small and Verheof 2007), especially in light of the comparatively large confidence intervals evidenced by Z-statistics of around 2. As can be expected, the alternative specific constant of LDVs is larger than that of public transportation modes; the only exception is column (1). At identical travel costs and speeds, consumers prefer LDVs on average, because of factors not included in the utility function (equation 4), such as privacy, convenience, etc.

The autoregressive term of the total mobility equation 1 is significant and 0.6 and 0.9 in columns (1) and (2) and consistently around 0.8 in columns (3) - (5). This suggests that $60-90 \%$ of total travel demand at time $t$ is determined by that at previous years. Using the results from column (4), the corresponding rate of equilibrium correction $\gamma_{1}-1=0.767-1=-0.233$ is negative and significant, which implies the variables to be cointegrated.

The habit coefficient is most easily interpretable in columns (3) - (5), where it represents the coefficient of the autoregressive term of the log-odds ratio in equation 8 . It suggests that between two consecutive time steps, around $90 \%$ of the relative preference of one mode over another is due to inertia, i.e., past choices-only slightly less than $10 \%$ of the relative preference is chosen freely at any time step.

The long-run GDP elasticities are around 0.4-0.5 for the 1945-2010 time period and around 0.2 for the reduced and more recent early 1960 s to 2010 period. In contrast, the logsum elasticity seems to have slightly increased when moving from the 1945-2010 time period to the 
1960s-2010 interval. The decline of the long-run GDP elasticities over time could result from the declining average demand growth over time, possibly due to increasing diminishing returns to travel, while the apparent increase in the logsum elasticity can be attributed to increasing sensitivity to traffic congestion. However, these differences turn out not to be significant at a $95 \%$ confidence interval, with the exception of the long-run GDP elasticity in column (4).

The adjusted $\mathrm{R}^{2}$ of all estimated models is very high-well over $90 \%$ of the variation from the mean of all dependent variables of the system of equations can be explained by the model. The null hypothesis of the Harvey Lagrange Multiplier test of no autocorrelation in each equation and the system of equations cannot be rejected in columns (3) and (4). However, the p-values in column (5) suggest possible autocorrelation with respect to total mobility and the system of equations. In contrast, if the habit term is specified as a lagged share (equation 8), the null hypothesis of no autocorrelation is rejected for every equation and the system in most cases. Under such conditions, the coefficient estimates are efficient but the confidence intervals are overestimated.

\section{Testing the Behavior of the Model}

Using the results from columns (4) and (5) in Table 1 and a reference year of 2010, four scenarios were formulated through 2100 , i.e., (i) a baseline run, (ii) the stabilization of per person travel demand through identical, across-the-board increases in travel costs, (iii) the impact of road traffic congestion through a declining average LDV speed by $0.5 \%$ per year, and (iv) an increase in air traffic congestion due to frozen 2010 runway capacity. Note that none of these scenarios represents a policy case or an expectation about how the future may unfold; the mere purpose of this activity is to test the behaviour of the model. Table 2 summarizes the key assumptions. 
Baseline Run

Using the regression results from columns (4) and (5) in Table 1 and the scenario variables from Table 2, Figure 3a illustrates the historical and projected future levels of per person travel demand by mode of transport. Assuming a TTB of 1.4 hours per person per day and a $2 \%$ annual growth in per person GDP, the projected 2100 per capita mobility is between 33,300 and $39,900 \mathrm{pkm}$. The key difference between these two cases can be attributed to the projected air traffic volume. The latter is higher with the estimated coefficients from the longer-term historical data set $(1945-2010)$ because of the stronger initial aviation growth before 1960 . Yet, until around 2040, these differences remain small. Due to the constrained TTB, per capita LDV travel is projected to peak during the 2020s, while the demand for low-speed public transportation continues its long-term decline. The rise in total per person travel demand can thus be attributed completely to the increase in higher-speed air transportation. If taking into account a $90 \%$ increase in the US population through 2100 (Middle Series projection from Census Bureau 2000), total PKT would multiply by a factor of 2.5 to 3.1 based on 2010 levels.

Figure $3 b$ depicts the sensitivity of the results with respect to differences in the TTB, using only the regression results underlying the 1960 - 2010 time series data (column (5) in Table 1). A larger TTB results in a lower VOT, which reduces the utility of each mode less strongly $\left(\beta_{3}<0\right)$, leading to higher levels of PKT (see equation 7). The projected increase in 2100 per person travel demand is from 33,300 pkm to 37,200 pkm for a TTB of 1.4 and 1.7 hours per person per day, respectively. The respective 2100 VOT results in $51 \%$ and $46 \%$ of the GDPbased wage rate (Figure $3 c$ ).

It is straightforward that a smaller TTB requires a larger amount of air transportation on the cost of automobile travel, while the amount of low-speed public transportation continues to 
decline in both time budget scenarios. Yet, irrespective of either of the two time budgets, the general trend toward air transportation remains unchanged. The differences in mode shares are depicted in Figure 3d.

[Figure 3a-d]

These projections can be compared to those from major aircraft manufacturers and the United Nations' International Civil Aviation Organization (ICAO). Notably, these bodies only project those RPK associated with air transportation. Typically, intra-regional traffic is projected with a simple static model using GDP and airfares as the explanatory variables, whereas crossregional traffic is projected with a gravity model using travel distance as an additional variable (e.g., ICAO 2004). Figure 4 depicts the air traffic trajectories related to those from Figure $3 a$ for domestic US traffic (using the Middle-Series projections of future US population growth [Census Bureau 2000] and a TTB of 1.4 and 1.7 hours per person per day), projections from the various bodies mentioned above, and the historical development of RPK in US domestic air traffic between 1950 and 2010. Typically, the growth in GDP per capita underlying these projections is around $2 \%$ per year, which is consistent with our projections. As can be seen, the range in RPK covered by the two air transportation-related trajectories from the baseline run is consistent with the range of industry and ICAO projections. By 2040, the total growth in US domestic air travel would be 2.0-2.4 times the 2010 level, corresponding to an average growth rate of $2.4-2.9 \%$ per year.

[Figure 4] 
Stabilization of Travel Demand per Person through Increases in Travel Costs

To explore the required increase in travel costs for per person travel demand to eventually level off, the 2010 travel costs per mode were increased by a uniform annual growth rate. The results in terms of per person PKT by mode are shown in Figure 5 for a GDP per capita growth of $2 \%$ per year and a TTB of $1.4 \mathrm{~h}$ per person per day. Achieving saturation of total PKT per person requires the average annual increase in travel costs for each mode to be $2.5 \%$ from the 2010 level (slightly larger than the per person GDP growth rate of $2 \%$ per year), resulting in almost 10-fold travel costs by 2100 . Yet, while per person travel would stabilize, total travel would continue to grow due to the anticipated increase in population by an average of $0.7 \%$ per year.

The simulated increase in travel costs is enormous, perhaps in part because it is based on the elasticities estimated for the historical 1960 - 2010 period. Over the next 90 years, the consumer responsiveness of travel to especially changes in income may decline, for example, due to diminishing returns to travel, and so would the required increase in travel cost. Yet, the large required increase in travel costs under today's conditions underlines the strength of the natural dynamics of the transportation system underlying the model presented here.

[Figure 5]

The Impact of Road Traffic Congestion on Passenger Travel

In addition to reducing vehicle speeds, traffic congestion increases operating costs mainly due to increased fuel use and the opportunity costs of travel time, i.e., the VOT. However, for simplicity, we only simulate first-order impacts by assuming a continuous decline in LDV speeds 
by $0.5 \%$ per year starting in 2021 . Given an average door-to-door travel speed of $47.4 \mathrm{~km} / \mathrm{h}$ in 2010, the 2100 level results in $31.6 \mathrm{~km} / \mathrm{h}$. Figure 6 reports the associated amount of PKT per person and mode for the base case and the road traffic congestion case, again for a GDP per capita growth of $2 \%$ per year and a travel time budget of $1.4 \mathrm{~h}$ per person per day.

Because of the reduced travel speed, per person LDV travel declines and causes a diversion toward less congested modes, i.e., public surface transportation and air traffic. The net effect of reduced LDV traffic and an increase in travel by the other, less congested modes is a nearly $25 \%$ decline of total per person PKT in 2100 compared to the baseline run. While automobile travel per person is projected to decline by some $40 \%$ compared to 2010 levels, air travel could grow by almost $20 \%$ and public surface transportation by more than $200 \%$.

[Figure 6]

The Impact of Air Traffic Delays on Passenger Travel

We now simulate the impact of fixed 2010 runway capacity on passenger travel. Extra airline operating costs due to traffic congestion are assumed to correspond to the operating costs in 2010 of $\$ 47.40$ per minute (Department of Transportation 2012). Because of the annual time steps taken here, airlines are expected to adjust their schedules to the increasing levels of traffic congestion and thus avoid the otherwise exponential growth in operating costs associated with schedule disruptions (see, e.g., Fearing and Barnhart 2011).

Figure 7 depicts the simulated implications. Per capita air travel is projected to saturate during the mid 2070 s and to subsequently decline. The decline is a consequence of the utilization ratio (equation 9) being dependent on total RPK instead of per person travel: for total 
RPK to continue to grow, per person RPK eventually has to decline. In 2100, per person air travel related PKT would be nearly $30 \%$ below the respective baseline level. The saturation and subsequent decline of total PKT per person mirrors that of air travel; the fixed TTB prevents slower transportation modes from absorbing lost air travel demand. During the 90 years time horizon, the simulated door-to-door air travel speed would decline from $302 \mathrm{~km} / \mathrm{h}$ in 2010 to 167 $\mathrm{km} / \mathrm{h}$ in 2100.

[Figure 7]

\section{Caveats}

Naturally, such an aggregate model has a number of caveats. Perhaps most importantly, the limited data availability allows the use of only GDP, travel costs, door-to-door speeds, and the GDP-based wage rate as explanatory variables. Those factors that have affected mobility and mode choice over a longer time period (e.g., convenience, comfort, privacy, etc.) are captured by the alternative specific constant of LDV and public surface transportation travel. Using the utility equation for LDVs from equations (3) with a logarithmic lagged share and introducing the coefficients from Table 1 (column 5) along with the 2010 values for vehicle speed $(47.4 \mathrm{~km} / \mathrm{h})$, travel costs $(0.171 \$ / \mathrm{pkm})$, and wage rate $(\$ 58.8 / \mathrm{h})$ yields

$$
\begin{aligned}
& V_{L D V, t}=\beta_{m}+\beta_{1} \ln \left(S h_{m, t-1}\right)+\beta_{3}\left(\frac{V O T}{S_{m, t}}+\frac{C_{m, t}}{(G D P / h)_{t}}\right) \\
& V_{L D V, t}=0.353-0.126-0.265
\end{aligned}
$$


Hence, around $53 \%$ of the LDV utility in 2010 can be explained by the employed variables $([0.126+0.265] /[0.353+0.126+0.265])$; the remaining $47 \%$ depends on those factors not explicitly included in the utility function.

In contrast, emerging trends such as the recent explosive growth of telecommunication devices is excluded from the model. Kamargianni and Polydoropoulou (2013) showed that the use of mobile Internet devises increases the amount of travel by certain groups of adolescents. The adoption of information and communication technologies also enables new business models within the transportation economy, for example relying on the sharing economy with an uncertain impact on travel demand. Other caveats include the use of average GDP instead of the income distribution. Given past trends toward increasing income inequality, this simplification may lead to slightly biased GDP elasticities as has been shown for US air transportation (see Joutz and Schäfer 2014). In addition, factors that are correlated with per person GDP, such as the increasing participation of women in the labor force, the dramatic increase in vehicle ownership, the resulting decline of vehicle occupancy rates as well as increasing levels of urbanization are not specifically modeled. Moreover, as referred to in the introduction, the simulated mode substitutions occur within two distinct markets (short- and longdistance), suggesting the use of a nested model (although the projected future mode changes are comparatively modest and the probability of aircraft displacing modes in short-distance travel thus small).

Alternative model specifications that overcome some of these simplifications have been and will continue to be tested. However, owing to its simplicity and plausibility of the results, the specification used in this paper was found to be a good reference point for further analysis. Yet, these and others caveats imply that the model results should be interpreted only as a first-order estimate of a future reference development against which the effectiveness of transportation policy measures or the impact of autonomous behavioral change can be assessed. 


\section{Conclusions}

The model presented in this paper consists of a system of three equations, which was estimated with time series data. In the absence of structural breaks, a fixed time budget constraint implies that the long-term historical trends toward higher levels of mobility and faster travel modes observed over the past 110 years may continue well into the future. Assuming an average growth rate of GDP per capita of $2 \%$ per year, US travel demand per person could increase by $30-50 \%$ by 2100 over the 2010 level, depending on the assumed travel time budget. If also accounting for the anticipated $90 \%$ growth in population during that period, total travel demand could multiply by a factor of 2.5 to 3.1 by 2100 .

The projected growth in total travel is mainly due to the increase in air transportation, which, over at least the next 20 years was found to be consistent with UN and aircraft industry projections. In contrast, LDV travel per person is projected to saturate and gradually decline; the year at which saturation occurs depends on the travel time budget; the higher the travel time budget, the later the year of "peak car". However, despite the saturation of per person LDV travel, the expected growth in population would continue to increase LDV travel, albeit at a significantly reduced rate.

Due to the long scenario time horizon and the limited number of attributes included in the utility functions of the three transportation modes, these projections can only serve as a benchmark development, against which alternative behavioral and technology futures can be evaluated. A number of potential structural breaks exists, ranging from behavioral change, for example caused by a change in values for today's adolescent population, at least partly 
supported by the penetration of mobile communication technologies, to the introduction of autonomous vehicles, which could relax the travel time budget constraint, as that time could be utilized more efficiently. Already, these two examples could lead to widely different transportation futures, i.e., a reduction of LDV travel in the first case in favor of low-speed public transportation means, and a potentially strong increase in automobile transport.

Yet, despite these uncertainties, the projected growth in total travel and the shift towards faster modes, along with the drastic measures necessary to mitigate these trends, demonstrate the stability of the natural dynamics underlying the transportation system, at least over the next several decades, even for high-income countries that could be expected to experience an eventual saturation of travel demand due to the finiteness of our transportation infrastructure and diminishing returns to travel.

\section{Acknowledgements}

The author is indebted to Moshe Ben-Akiva and Frederik Joutz for invaluable econometric advice and thankful to Jim Sweeney for stimulating discussions. Three unknown referees provided constructive comments, which helped improving the quality of the paper. Any misconceptions and errors remain the author's sole responsibility. The funding provided by 
Stanford University's Precourt Energy Efficiency Center that enabled this work is gratefully acknowledged.

\section{References}

Airbus (1996-2012) Global Market Forecast. Blagnac Cedex, France

Ben-Akiva ME, Lerman SR (1985) Discrete Choice Analysis. MIT Press.

Ben-Akiva ME (2013) Modeling and Simulation for Future Urban Mobility. Working paper, ITS

Lab, Department of Civil and Environmental Engineering, MIT.

Boeing (1997-2011) Current Market Outlook. Commercial Airplanes, Seattle WA.

Census Bureau (2000) Annual Projections of the Total Resident Population as of July 1: Middle, Lowest, Highest, and Zero International Migration Series, 1999 to 2100, Washington, DC. http://www.census.gov/population/projections/files/natproj/summary/np-t1.txt

Department for Transport (2009) National Transport Model: High Level Overview. London, UK. http://webarchive.nationalarchives.gov.uk/20110202223628/http:/www.dft.gov.uk/pgr/econ omics/ntm/

Department of Transportation (2012) Airline On-Time Performance Data.

http://www.transtats.bts.gov/Fields.asp?Table_ID=236

Department of Transportation (2013) National Household Travel Survey, Online Analysis Tool. http://nhts.ornl.gov

Energy Information Administration, EIA (2009) The National Energy Modeling System: An

Overview. Office of Integrated Analysis and Forecasting, Department of Energy, Washington, DC.

Fearing D, Barnhart C (2011) Evaluating Air Traffic Flow Management in a Collaborative Decision-Making Environment. Transportation Research Record 2206 (2011): 10-18. 
Fulton L, Cazzola P, Cuenot F (2009) IEA Mobility Model (MoMo) and its Use in the ETP 2008. Energy Policy 37:3758-3768.

Goodwin P (2012) Peak Travel, Peak Car and the Future of Mobility. Discussion Paper 2012, No.13. International Transport Forum, OECD.

Gross D, Shortle JF, Thompson JM, Harris CM (2008) Fundamentals of Queuing Theory, fourth Edition, Wiley.

International Civil Aviation Organization, ICAO (1990, 1995, 1997, 2001, 2004, 2007) Outlook for Air Transport, Montreal.

Joutz F, Schäfer A (2014) Income Distribution Effects on U.S. Air Travel Demand, Draft Paper, Precourt Energy Efficiency Center, Stanford University.

Kamargianni M, Polydoropoulou A (2013) Does Social Networking Substitute for or Stimulate Teenagers' Travel? Findings from a Latent Class Model. 3rd International Choice Modeling Conference (ICMC), 3-5 July, 2013, Sydney, Australia. http://www.icmconference.org.uk/index.php/icmc/ICMC2013/paper/viewFile/761/353 Marchetti C (1994) Anthropological Invariants in Travel Behavior. Technological Forecasting and Social Change 47:75-88.

Millard-Ball A, Schipper L (2010) Are We Reaching Peak Travel? Trends in Passenger Transport in Eight Industrialized Countries. Transport Reviews 31:357-378.

Mokhtarian PL, Chen C (2004) TTB or not TTB, that is the Question: A Review and Analysis of the Empirical Literature on Travel Time (and Money) Budgets, Transportation Research Part A, 38(9-10): 643-675.

Schäfer A (2013) Evolution of Transportation Demand, Technological Change, and Energy Use in the US Transportation Sector since 1900. Draft Paper, Precourt Energy Efficiency Center, Stanford University.

Schäfer A, Heywood JB, Jacoby HD, Waitz IA (2009) Transportation in a Climate-Constrained World. MIT Press. 
Schäfer A, Victor DG (2000) The Future Mobility of the World Population, Transportation Research Part A, 34(3): 171-205.

Small KA, Verhoef ET (2007) The Economics of Urban Transportation. Routledge, London and New York.

Zahavi, Y (1981) The UMOT-Urban Interactions. DOT-RSPA-DPB 10/7. Department of Transportation, Washington, DC.

Zmud J, Ecola L, Phleps P, Feige I (2013) The Future of Mobility-Scenarios for the United States in 2030. RAND Corporation, Santa Monica, CA. 
Table 1 Parameter estimates, $z$ statistics (in parenthesis), and regression statistics for the Autoregressive Distributed Lag total mobility model estimated simultaneously with the MNL model via SUR.

\begin{tabular}{|c|c|c|c|c|c|}
\hline & (1) & (2) & (3) & (4) & (5) \\
\hline Equations used & 1,7 & 1,7 & 1,8 & 1,8 & 1,8 \\
\hline Underlying Data Series & $1945-2010$ & $1961-2010$ & $1945-2010$ & $1945-2010$ & $1960-2010$ \\
\hline No. Observations & $65 \times 3$ & $50 \times 3$ & $65 \times 3$ & $65 \times 3$ & $51 \times 3$ \\
\hline \multicolumn{6}{|l|}{ Adjusted $\mathrm{R}^{2}$} \\
\hline Total Mobility & 0.9965 & 0.9982 & 0.9960 & 0.9959 & 0.9982 \\
\hline Odds Ratio LDV/HST & 0.9373 & 0.9334 & 0.9965 & 0.9966 & 0.9935 \\
\hline Odds Ratio PUB/HST & 0.9673 & 0.9217 & 0.9979 & 0.9979 & 0.9968 \\
\hline \multicolumn{6}{|l|}{ Harvey LM Test $\left(p>x^{2}\right)$} \\
\hline Total Mobility & 0.0009 & 0.0000 & 0.3153 & 0.3229 & 0.0001 \\
\hline Odds Ratio LDV/HST & 0.0000 & 0.0000 & 0.1811 & 0.1817 & 0.0808 \\
\hline Odds Ratio PUB/HST & 0.0000 & 0.0000 & 0.2836 & 0.2853 & 0.5799 \\
\hline System $\left(x^{2}(3)\right)$ & 0.0000 & 0.0000 & 0.2673 & 0.2722 & 0.0002 \\
\hline Constant (Yo) & $1.686(7.74)$ & $0.846(4.40)$ & $1.405(4.84)$ & $1.400(4.93)$ & $1.604(6.89)$ \\
\hline Autoregressive term $\left(\gamma_{1}\right)$ & $0.597(10.8)$ & $0.870(22.2)$ & $0.766(17.5)$ & $0.767(17.9)$ & $0.817(21.0)$ \\
\hline GDP/cap, SR multiplier $\left(\gamma_{2}\right)$ & $0.258(3.34)$ & $0.355(5.97)$ & $0.226(3.48)$ & $0.230(3.55)$ & $0.257(4.95)$ \\
\hline Lagged GDP/cap $\left(\gamma_{3}\right)$ & $-0.038(-0.61)^{8 \S}$ & $-0.329(-5.56)$ & $-0.125(-2.30)$ & $-0.130(-2.44)$ & $-0.220(-4.08)$ \\
\hline Logsum, SR multiplier $\left(\mathrm{Y}_{4}\right)$ & $0.079(3.70)$ & $0.012(2.64)$ & $0.056(1.84)^{\S}$ & $0.055(2.07)$ & $0.060(3.09)$ \\
\hline Dummy variable & $-0.030(-3.75)$ & $-0.032(-7.40)$ & $-0.025(-3.72)$ & $-0.024(-3.63)$ & $-0.027(-7.59)$ \\
\hline ASC LDV ( $\left(\beta_{L D V}\right)$ & $-1.748(-3.28)$ & $2.249(5.50)$ & $0.240(5.03)$ & $0.239(10.6)$ & $0.353(4.04)$ \\
\hline Habit coefficient $\left(\beta_{1}\right)$ & $5.797(13.8)$ & $1.286(3.47)$ & $0.908(126)$ & $0.908(129)$ & $0.904(61.4)$ \\
\hline Generalized cost coeff. $\left(\beta_{3}\right)$ & $-291(-35.3)$ & $-403(-23.1)$ & $-20.6(-6.85)$ & $-20.6(-7.45)$ & $-28.7(-4.43)$ \\
\hline Value of time (VOT) & $0.110(1.87)^{\S}$ & $0.124(2.14)$ & $0.112(0.84)^{8 \S}$ & 0.11 & $0.300(2.07)$ \\
\hline ASC PUB ( $\left(\beta_{P U B}\right)$ & $0.304(0.44)^{\S 3}$ & $0.607(0.68)^{8 \S}$ & $-0.073(-0.66)^{\S \S}$ & $-0.075(-7.45)$ & $0.161(1.10)^{8 \varsigma}$ \\
\hline \multicolumn{6}{|l|}{ Long-Run Elasticiti } \\
\hline $\operatorname{GDP}\left(\gamma_{2}+\gamma_{3}\right) /\left(1-\gamma_{1}\right)$ & $0.545(27.1)$ & $0.232(1.87)^{\S}$ & $0.431(8.53)$ & $0.428(10.6)$ & $0.202(2.61)$ \\
\hline logsum $\left(\gamma_{4} /\left(1-\gamma_{1}\right)\right)$ & $0.197(4.93)$ & $0.346(2.46)$ & $0.237(2.08)$ & $0.237(2.60)$ & $0.328(2.72)$ \\
\hline
\end{tabular}

Table Notes:

${ }^{\S}$ Significant at the $90 \%$ confidence level; ${ }^{\S}$ not significant at $90 \%$ confidence level Impulse is 1 in 1974, 1979, 1991, 2008, and 2010, otherwise 0. 
Table 2 Key scenario assumptions

\begin{tabular}{|c|c|c|c|c|}
\hline & Baseline & $\begin{array}{l}\text { Stabilizing } \\
\text { PK/cap }\end{array}$ & $\begin{array}{l}\text { Road Traffic } \\
\text { Congestion }\end{array}$ & $\begin{array}{c}\text { Fixed Runway } \\
\text { Capacity }\end{array}$ \\
\hline GDP per capita growth rate, $\% / y r$ & 2.0 & 2.0 & 2.0 & 2.0 \\
\hline Wage rate growth rate, $\% / y r$ & 2.0 & 2.0 & 2.0 & 2.0 \\
\hline Population growth rate, $\% / y r$ & 0.7 & 0.7 & 0.7 & 0.7 \\
\hline Coefficients used from Table 2 , column & 4,5 & 5 & 5 & 5 \\
\hline Travel time budget in $2100, \mathrm{~h} / \mathrm{cap} / \mathrm{d}$ & $1.4,1.7$ & 1.4 & 1.4 & 1.7 \\
\hline \multicolumn{5}{|l|}{ Change in travel speeds, \%/yr } \\
\hline Aircraft & 0.0 & 0.0 & 0.0 & $-0.9^{(2)}$ \\
\hline Light-duty vehicles & 0.0 & 0.0 & $-0.5^{(1)}$ & 0.0 \\
\hline Public surface & 0.0 & 0.0 & 0.0 & 0.0 \\
\hline \multicolumn{5}{|l|}{ Change in travel costs, \%/yr } \\
\hline Aircraft & 0.0 & $2.6^{(2)}$ & 0.0 & $1.4^{(2)}$ \\
\hline Light-duty vehicles & 0.0 & $2.6^{(2)}$ & 0.0 & 0.0 \\
\hline Public surface & 0.0 & $2.6^{(2)}$ & 0.0 & 0.0 \\
\hline
\end{tabular}

(1) Starting in 2020

(2) Result of the analysis 


\section{List of Figures}

Figure 1 Evolution of US passenger travel between 1900 and 2010: per person PKT by mode and total PKT (a) and mode shares (b).

Figure 2 Determinants of aggregate passenger travel: Per person GDP (a), population (b), wage rate (c), travel costs by mode (d), travel speeds by mode (e), daily amount of travel time per person for cities (59 data points) and African villages and cities (48 data points) and the use of time dedicated to motorized travel within the domestic US from 1946 to 2010 (f). Source: Schäfer (2013).

Figure 3 Historical data (1900-2010) and baseline run results (2011-2100) for per person PKT using regression results from columns (4) and (5) from Table 2 (a), for regression results of column (5) and two travel time budgets: per person PKT for (b), mode shares (c), and the value of time development (d), respectively.

Figure 4 Historical data (1950-2010), industry projections, and projected total domestic aviation-related PKT for travel time budgets of 1.4 and 1.7 hours per person per day. Source for industry projections: Airbus (1996-2012), Boeing (1997-2011), ICAO (1990, 1995, 1997, 2001, 2004, 2007).

Figure 5 Historical data (1960-2010) and scenario results (2011-2100) for per person PKT when stabilizing per person travel demand through across-the-board increases in travel costs.

Figure 6 Historical data (1900-2010) and scenario results $(2050,2100)$ for per person PKT under the road traffic congestion scenario.

Figure 7 Historical data (1950-2010) and scenario results (2011-2100) for per person PKT (a) and air travel door-to-door speed (b) under frozen 2010 US runway capacity. 


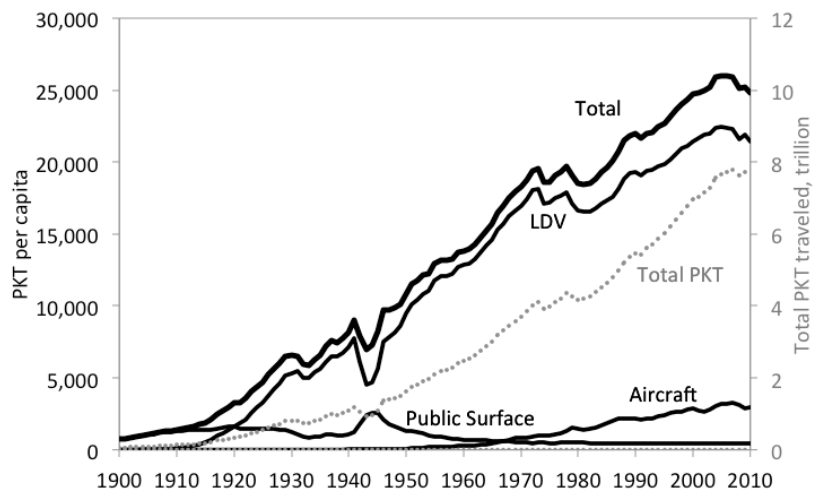

(a)

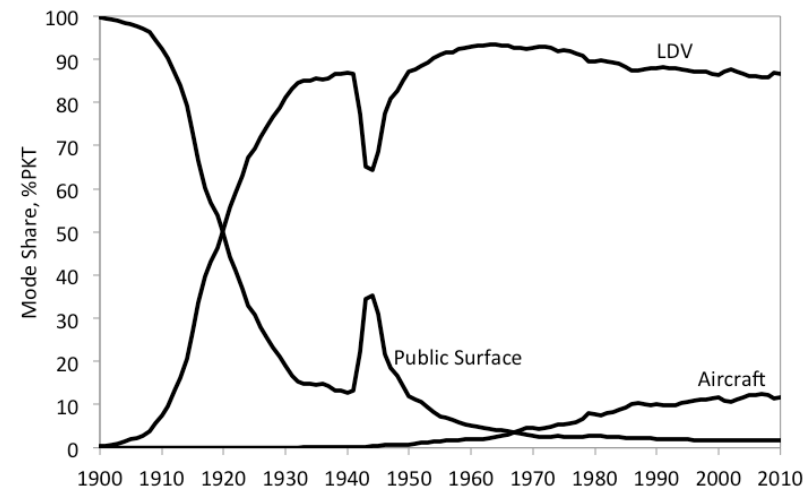

(b)

Figure 1 


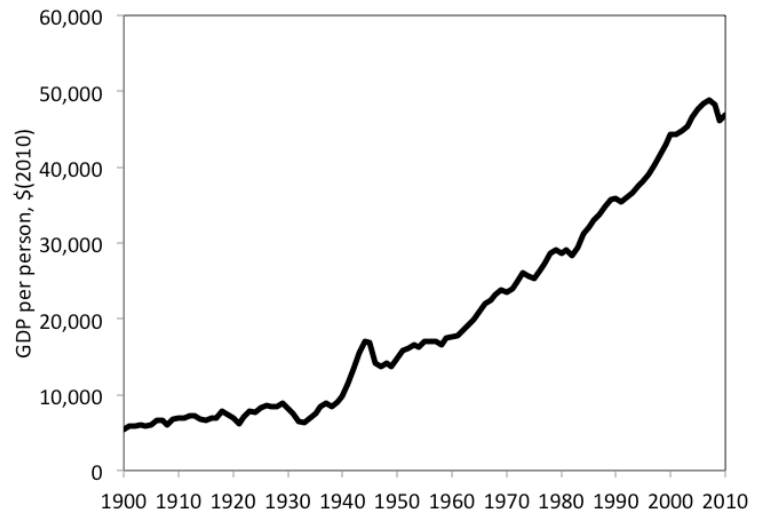

(a)

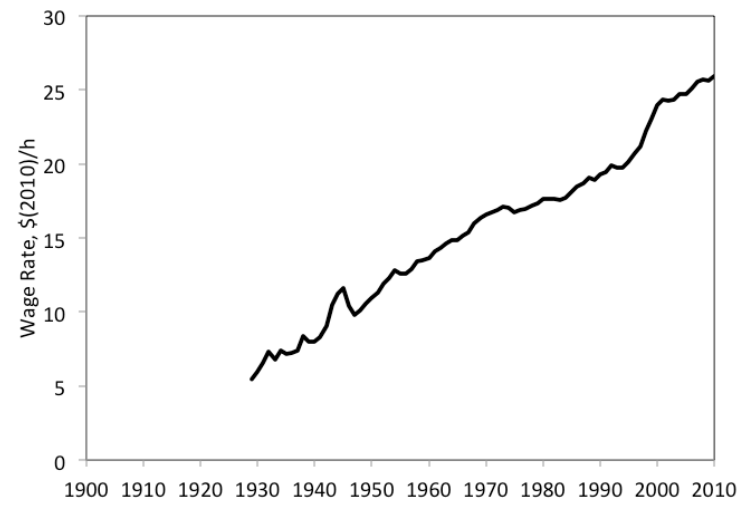

(c)

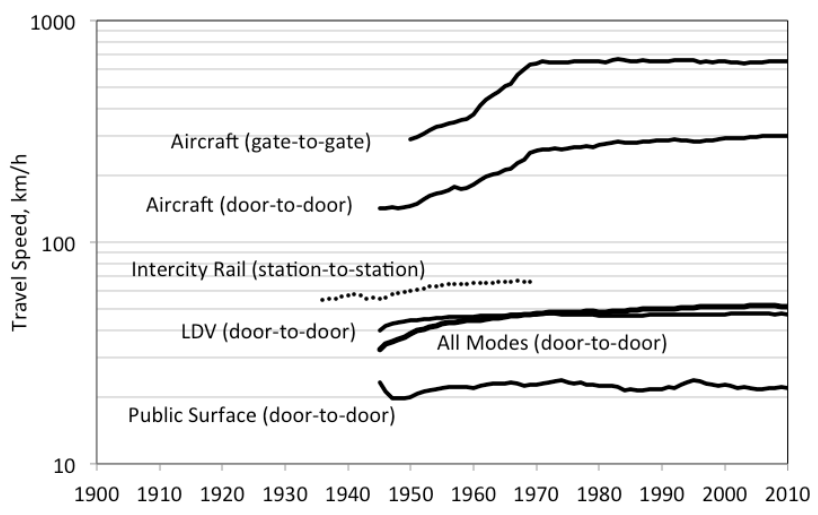

(e)

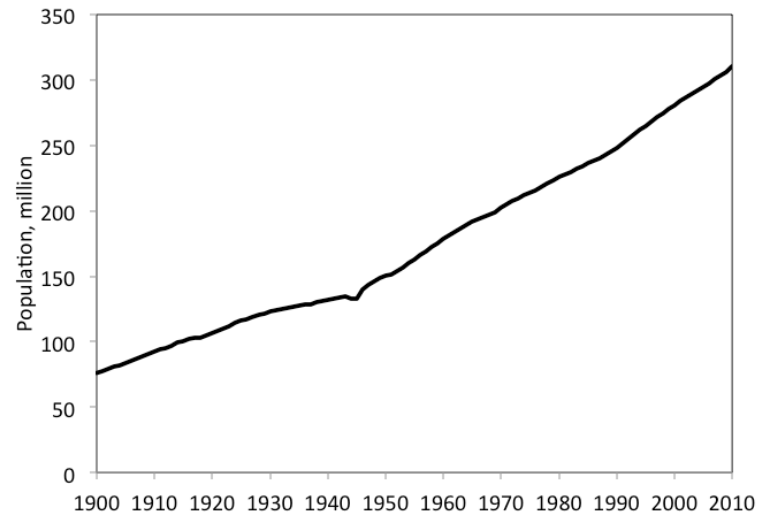

(b)

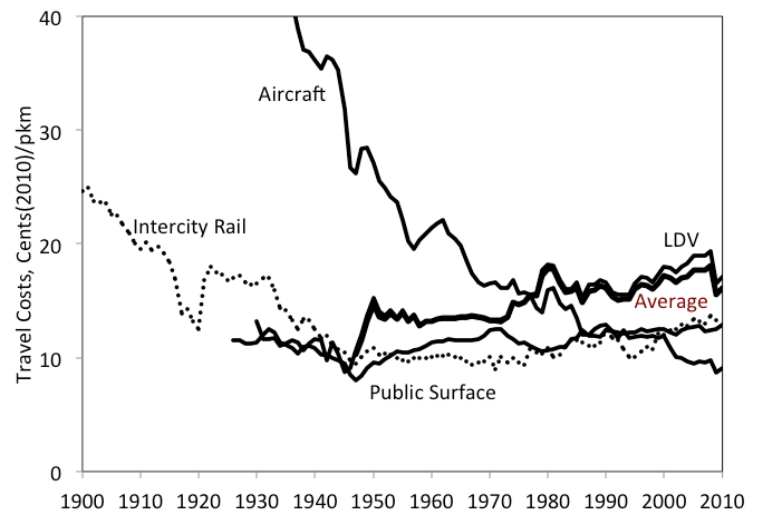

(d)

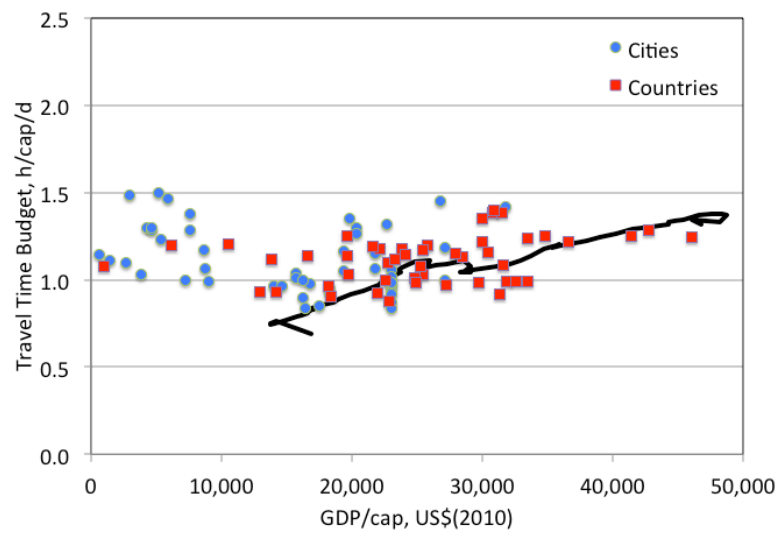

(f)

Figure 2 


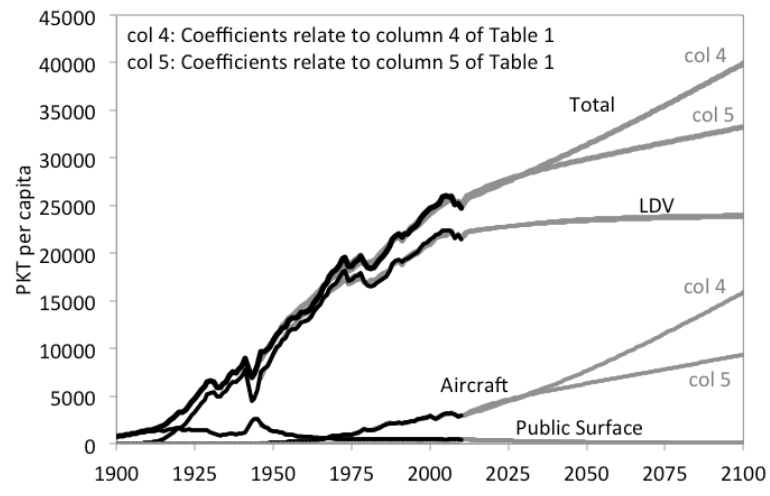

(a)

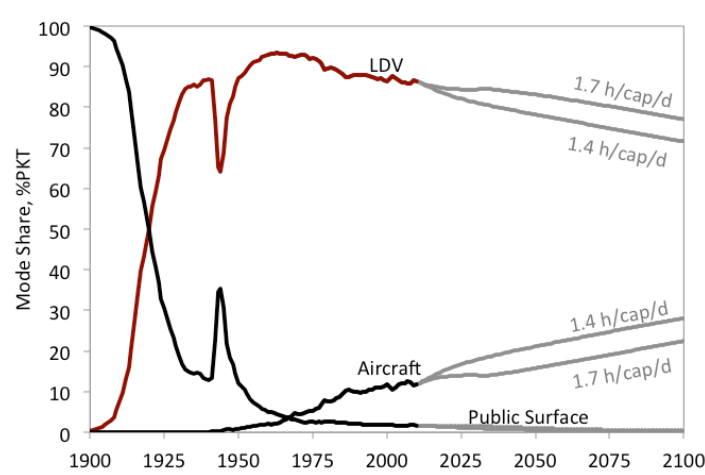

(c)

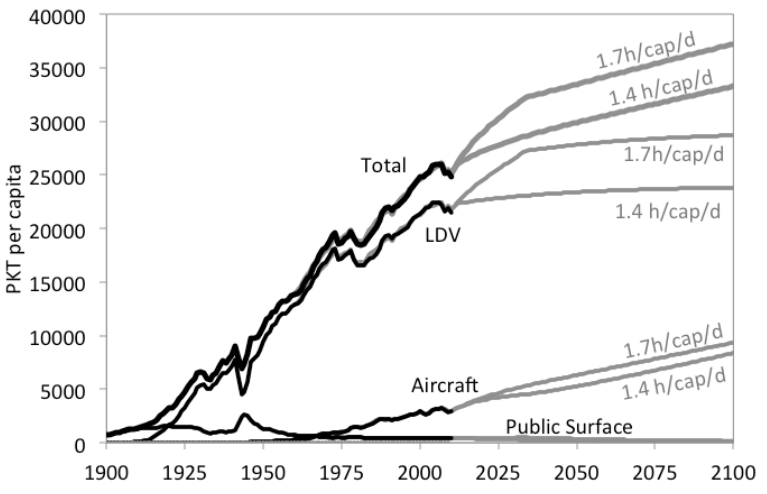

(b)

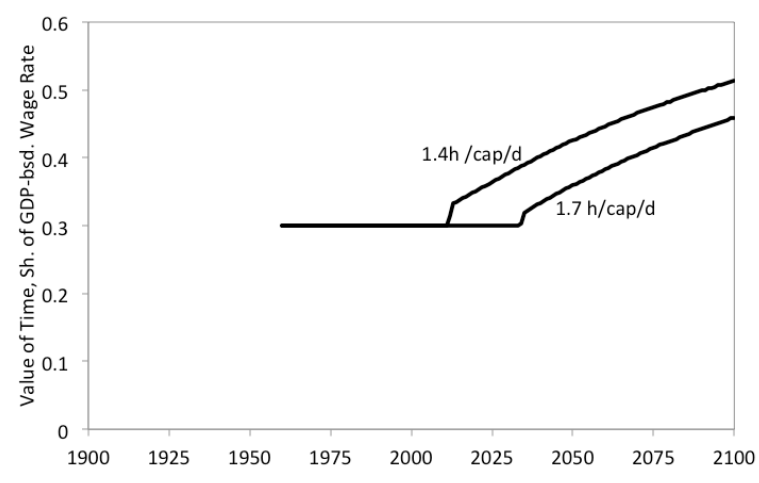

(d)

Figure 3 


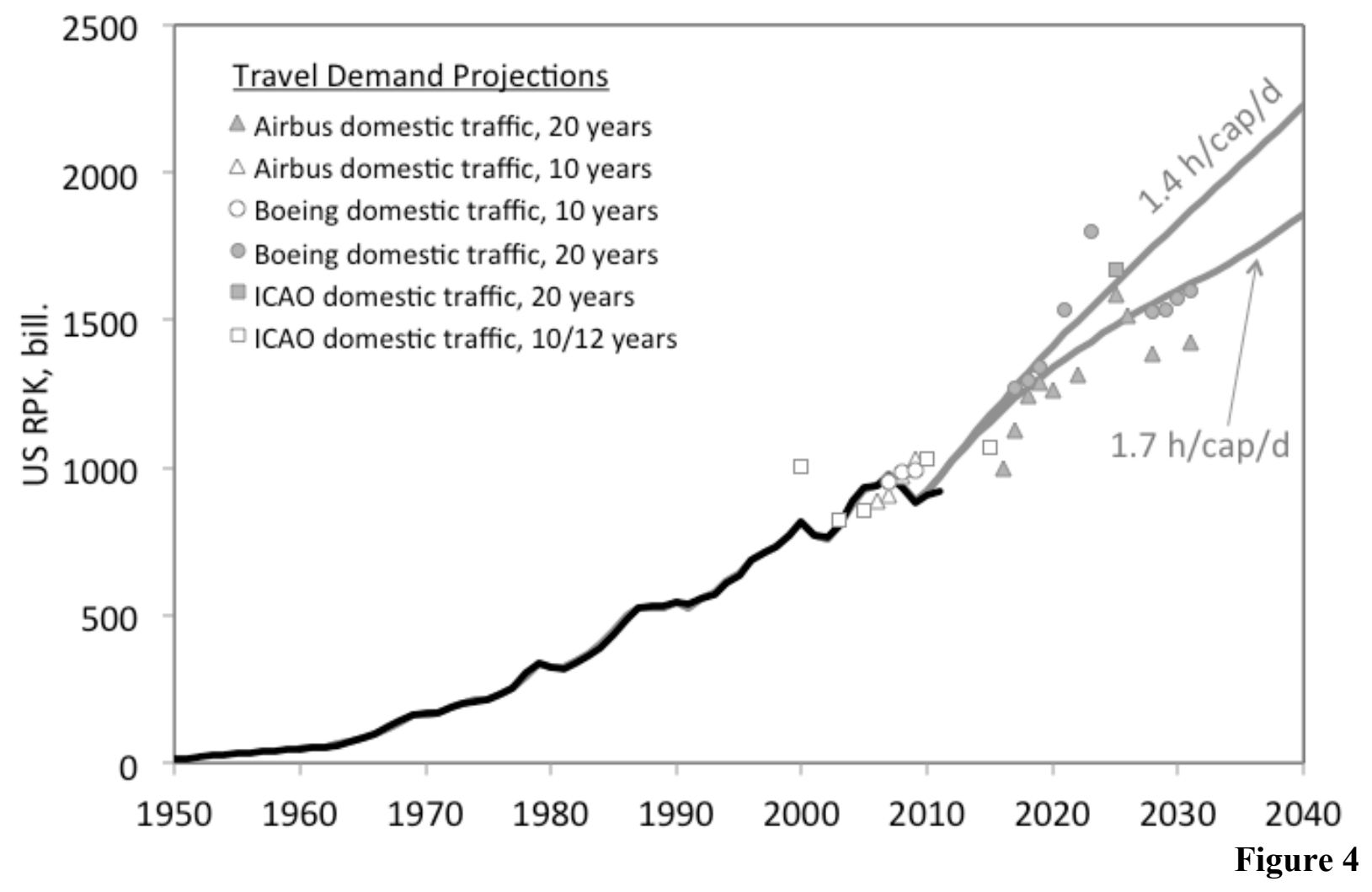




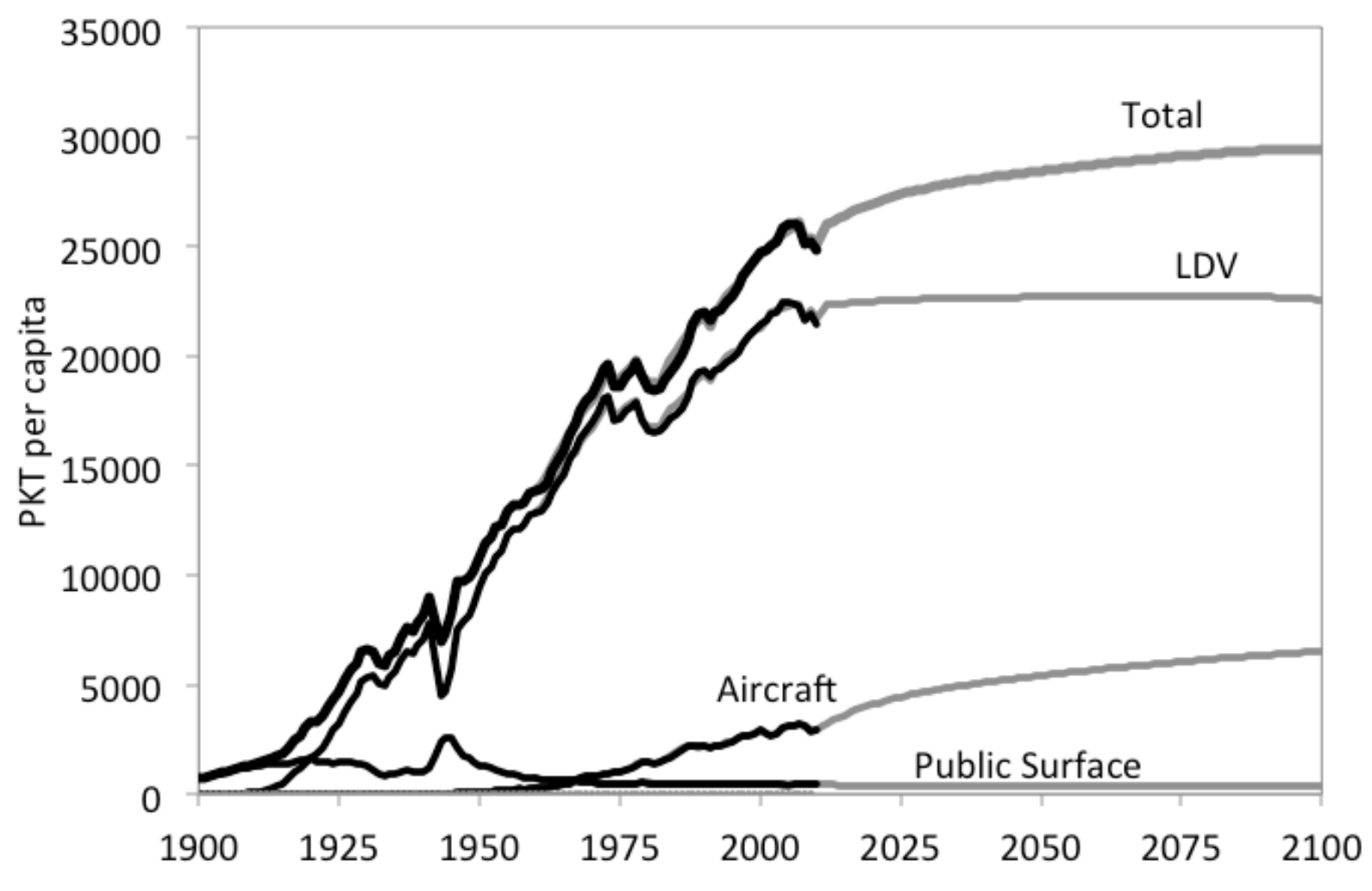

Figure 5 


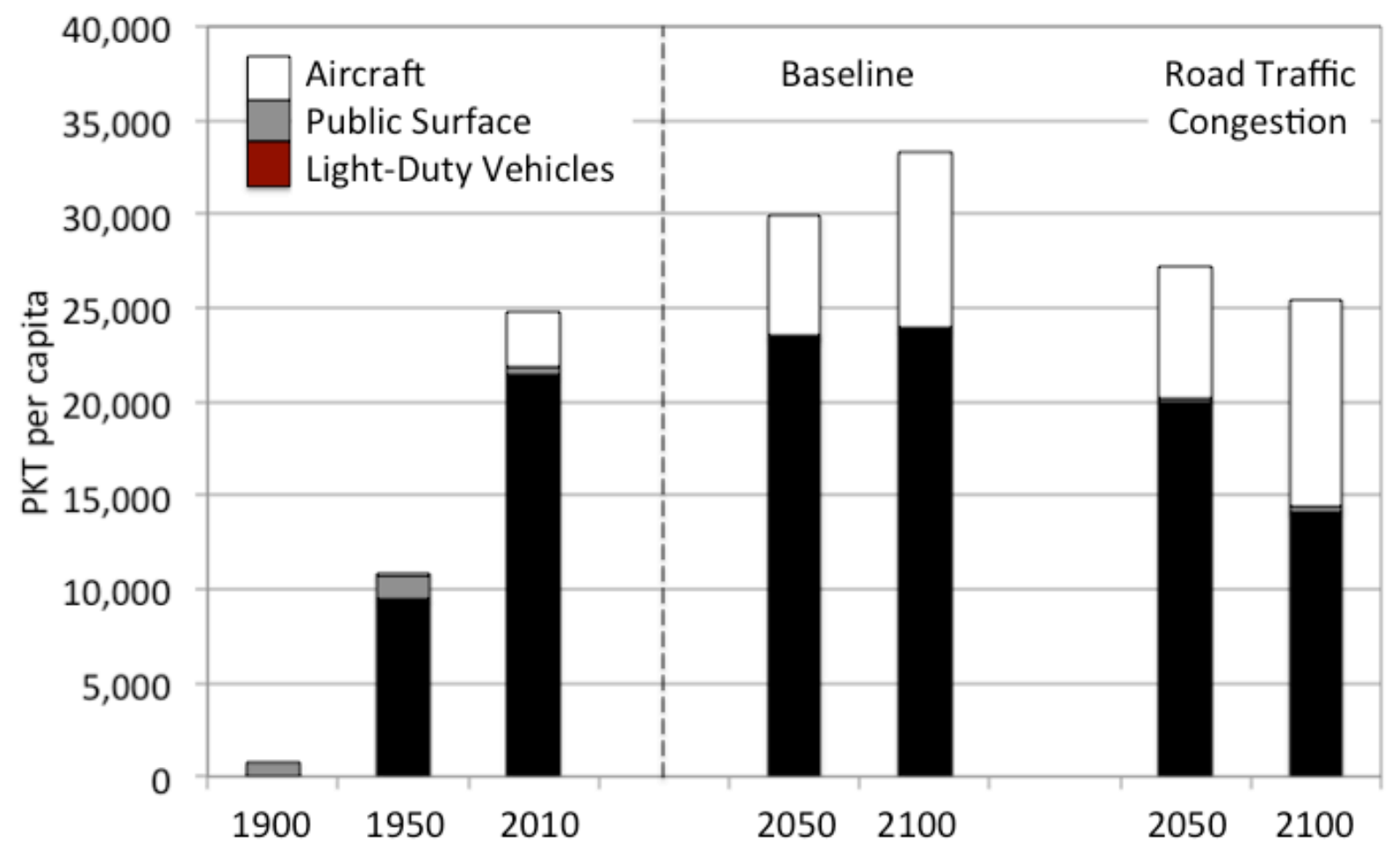

Figure 6 


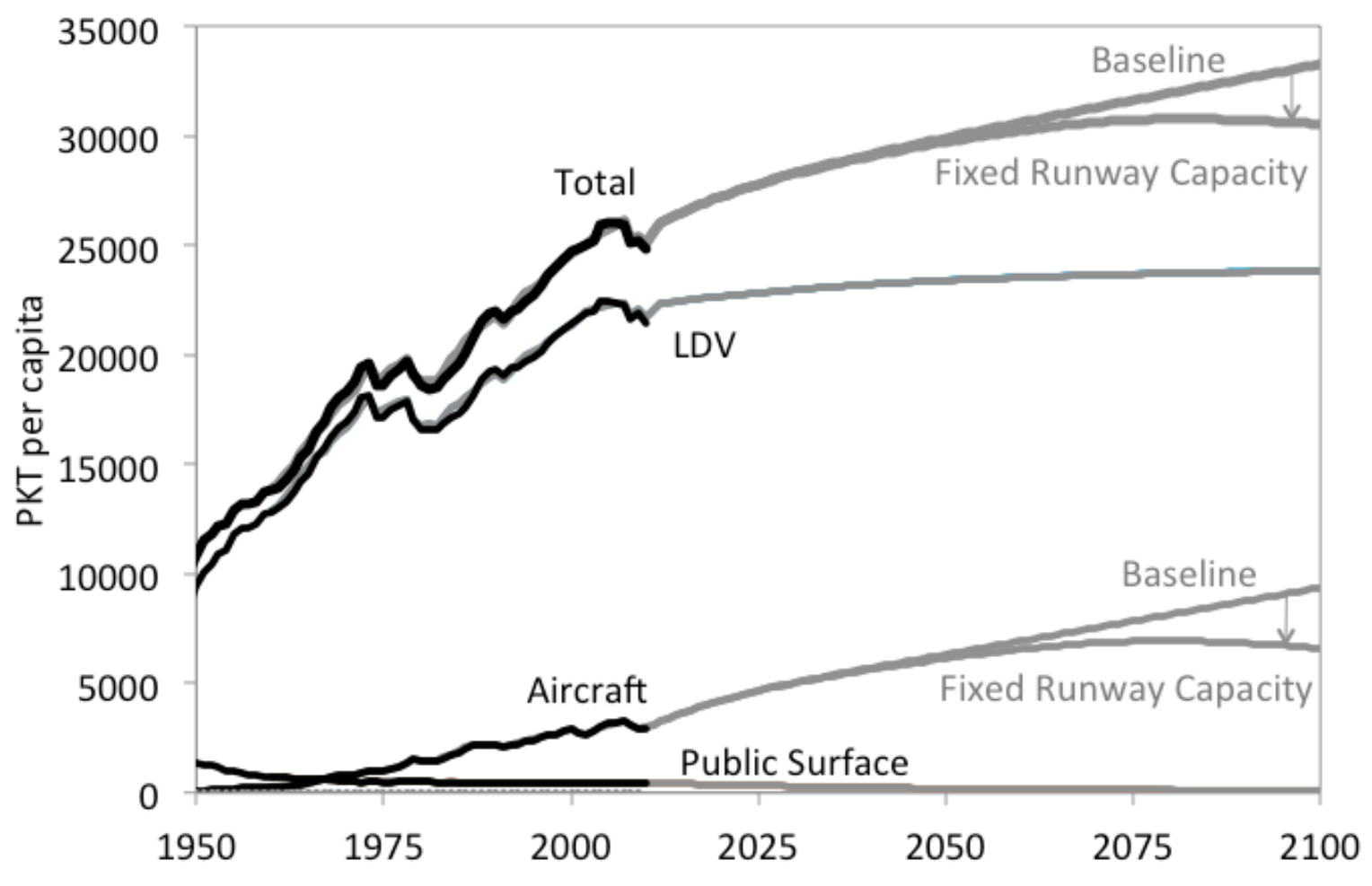

Figure 7 